\title{
Mecanismos generales y especiales de revisión administrativa de las sanciones
}

\author{
Rosa Gómez González*
}

\begin{abstract}
RESUMEN
Este artículo tiene por objeto dar cuenta de los mecanismos administrativos que existen para la revisión de las sanciones administrativas. La hipótesis central de la investigación plantea que no obstante la plena vigencia del principio de legalidad en materia administrativa sancionadora, no siempre una sanción producirá sus efectos jurídicos, pudiendo, en consecuencia, no ejecutarse. En este trabajo se ha podido determinar que en materia de sanciones administrativas es apropiado aplicar los mecanismos generales de revisión de oficio de los actos administrativos, así como también de ciertos mecanismos especiales en sectores de referencia dispuestos para revisión de actos sancionatorios, los que si bien tienen fundamentos jurídicos diversos, en general producen la extinción de la sanción administrativa impuesta, ya sea de manera definitiva o mediante su reemplazo por un acto administrativo diverso.
\end{abstract}

Derecho administrativo sancionador; invalidación; revocación

\section{General and special mechanisms of administrative review of sanctions}

\begin{abstract}
This article is intended to account for the administrative mechanisms that exist for the review of administrative sanctions. The central hypothesis of the investigation states that notwithstanding the full validity of the principle of legality in disciplinary administrative matters, a sanction will not always produce its legal effects, and may therefore not be executed. In this work it has been possible to determine that in the matter of administrative sanctions it is possible to apply
\end{abstract}

* Licenciada en Ciencias Jurídicas, Universidad de Talca, Chile. Doctora en Derecho, Pontificia Universidad Católica de Valparaíso, Chile. Profesora e investigadora, Pontificia Universidad Católica de Valparaíso, Chile. Correo electrónico: f.gomez.g@pucv.cl

Esta investigación cuenta con el apoyo del Proyecto Fondecyt Postdoctoral No 3190494 "Sanciones administrativas y derechos fundamentales. Análisis de temas específicos a partir de los principios, garantías y derechos regulados en la Constitución” y del Fondecyt Regular No 359974 "Criterios y estándares para el control de la potestad sancionadora de la Administración: análisis de los mecanismos de revisión judicial y administrativa". Asimismo, cuenta con el apoyo del proyecto de investigación "Derecho Administrativo Sancionador 2.0” (2018-RTI-096688-B-100), Proyecto I+D+i “Retos Investigación” 2018, del Ministerio de Ciencia, Innovación y Universidades de España y del Fondo Europeo de Desarrollo Regional (FEDER).

Artículo recibido el 13.3.2019 y aceptado para su publicación el 3.9.2019. 
the general mechanisms of ex officio review of administrative acts as well as certain special mechanisms in reference sectors arranged for review of sanctioning acts, which although have Various legal bases, in general, result in the extinction of the administrative sanction imposed, either definitively or by replacing it with a different administrative act.

Sanctioning administrative law; invalidation; revocation

\section{Aspectos Generales}

$\mathrm{E}$ 1 análisis de los mecanismos de revisión de las sanciones administrativas nos sitúa en la etapa de ejecución de las medidas represivas impuestas, buscando determinar si la sanción debe o no producir sus efectos jurídicos. Por regla general, el principio de legalidad exige que toda sanción debe ser ejecutada en los términos previstos en el acto administrativo que la establece, sin embargo, el ordenamiento jurídico nacional ha contemplado distintos mecanismos que permiten a la autoridad revisar el acto administrativo sancionador.

Por medio de los mecanismos de revisión se busca determinar si la sanción administrativa impuesta producirá sus efectos jurídicos, para ello se revisará si el acto sancionador adolece de algún vicio de legalidad o si es posible ejecutar la sanción impuesta resulta conforme a los fines de interés general.

De este modo la hipótesis central de esta investigación plantea que no obstante la plena vigencia del principio de legalidad en materia administrativa sancionadora, no siempre una sanción administrativa producirá sus efectos jurídicos, pudiendo, en consecuencia, no ejecutarse, extinguiéndose con ello la responsabilidad administrativa o, en su caso, sustituyéndose la sanción por otra medida administrativa. Ahora bien, en algunos casos, como en la invalidación, la extinción del acto sancionatorio no impedirá que la autoridad pueda perseguir, en un nuevo procedimiento administrativo, la responsabilidad del infractor, ello en la medida que la infracción no se encuentre prescrita.

A continuación se dará cuenta del fundamento de la revisión administrativa de los actos sancionatorios (II), para enseguida analizar los mecanismos de revisión general y especiales contemplados en nuestro ordenamiento jurídico (III y IV) para finalizar con algunas conclusiones (V).

\section{Fundamento de la REVISIÓN DE los ACTOS ADMinistrativos SANCIONATORIOS}

Existen circunstancias en que por diversos motivos la aplicación de la sanción establecida puede no ser procedente, atendida la existencia de motivos de ilegalidad que afecten el acto que la contiene, que existan vicios en el procedimiento con el que se estableció la medida o que, por motivos de prudencia, sea desaconsejable su imposición ya que puede no resultar adecuada a una situación concreta y desbordar el ámbito de lo razonable, por ejemplo, si la imposición de la multa puede causar mayores perjuicios 
al interés público comprometido, como la quiebra de un contribuyente o el cierre de la empresa. En estos supuestos, la aplicación de la sanción no logra satisfacer los fines que la Administración persigue y, en alguno de ellos, la imposición de esta puede resultar contraria al interés general que se busca garantizar en el caso en concreto.

Para hacer frente a esta problemática, es acertado analizar los diversos mecanismos de que dispone la Administración para revisar la pertinencia de la ejecución de la sanción administrativa impuesta, sea que dicha revisión encuentre su sustento en motivos de legalidad o en razones de mérito, conveniencia u oportunidad.

En una primera aproximación, se podría sostener que no es posible que la Administración pueda disponer de dicha determinación en este ámbito, por lo que una vez dictado el acto sancionatorio solo corresponde exigir su cumplimiento ${ }^{1}$. Esta afirmación encuentra su sustento en la plena vigencia del principio de legalidad en este ámbito, en el que la sanción administrativa es el resultado de una potestad administrativa estrictamente reglada.

Sin embargo, nuestra legislación ha proporcionado a la autoridad administrativa distintos mecanismos de revisión de los actos sancionatorios. Así, con carácter general, la Administración dispone de la potestad de revisión, la que puede concretar mediante la invalidación o la revocación del acto respectivo, pero también puede la autoridad dar lugar a la doctrina del decaimiento del acto administrativo sancionatorio. Por su parte, en algunos sectores especiales, las leyes han otorgado a la Administración ciertos mecanismos destinados a dejar sin efecto o reemplazar la sanción aplicada por una medida que estime más idónea para la consecución de sus fines, como sería disponer de la condonación, sustitución o suspensión de la sanción impuesta. De todos estos mecanismos se dará cuenta en los apartados siguientes, teniendo presente que para su desarrollo se tendrá en consideración su importancia o mayor o menor discusión existente en la doctrina y jurisprudencia respecto de cada uno de dichos mecanismos.

En general, la aplicación de cualquiera de estos mecanismos (generales o especiales) extingue la sanción administrativa, la que no llegará a ejecutarse, sea por la desaparición del acto administrativo que la impone o por el reemplazo por otra medida. Cuestión aparte es la existencia de la infracción, la que en alguno de estos supuestos podrá ser perseguida nuevamente con el objeto de establecer la responsabilidad del infractor, como ocurre en el caso de la invalidación, a menos que el plazo para perseguir la responsabilidad administrativa por tal infracción haya prescrito.

Ahora bien, la diferencia entre los mecanismos generales y especiales radica en que mientras los primeros se pueden aplicar a cualquier acto administrativo sancionador, los segundos solo proceden respecto de aquellos ámbitos sectoriales en los que la ley los haya previsto expresamente.

${ }^{1}$ En Chile, el acto administrativo sancionador produce inmediata ejecutoriedad, y los recursos no suspenden su ejecución, salvo que se ordene lo contrario (artículo $3^{\circ}$ inciso final, 51 y 57 LBPA). Resulta pertinente la distinción acerca de la ejecutoriedad y ejecutividad analizada en la sentencia de la Corte

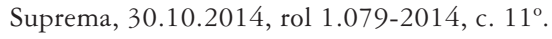




\section{MECANismos DE REVISIÓN GENERALES}

La Ley 19.880, de 2003, sobre bases generales de los procedimientos administrativos (en adelante LBPA), incorporó en el Capítulo IV, relativo a la "Revisión de los actos administrativos”, la potestad de invalidación (artículo 53) y revocación (artículo 61) de los actos administrativos, como formas generales de revisión de los actos administrativos $^{2}$, las que ciertamente son aplicables a los actos administrativos de carácter sancionador, siendo necesario analizar la forma en donde se pueden ejercer las aludidas potestades en dicho ámbito.

Por su parte, en cuanto a la doctrina del decaimiento, si bien ha sido invocada en nuestro ordenamiento por la jurisprudencia judicial, la forma en que ha sido aplicada se distancia de sus bases dogmáticas, siendo necesario analizar su incidencia en la ejecución de las sanciones administrativas a partir de su concepción original.

\section{La invalidación}

\section{a) Antecedentes generales}

Recordemos que la invalidación ha sido definida como una forma de extinción del acto administrativo (junto con la caducidad y la revocación), consistente en el retiro de aquel del mundo jurídico debido a que adolece de un vicio que lo hace contrario a Derecho $^{3}$, es decir, por infracción al principio de juridicidad establecido en los artículos $6^{\circ}$ y $7^{\circ}$ de la Constitución y $2^{\circ}$ de la Ley 18.575 , de Bases Generales de la Administración del Estado. La invalidación supone por ello una calificación jurídica de contraste entre el acto administrativo y las normas que prevé el ordenamiento para su dictación ${ }^{4}$.

La invalidación se caracteriza por ser una potestad reglada, toda vez que las condiciones para su ejercicio han sido expresamente configuradas por la ley. Es por ello por lo que la Contraloría General ha señalado que su ejercicio no solamente corresponde a una facultad de los órganos administrativos, sino que también a un "deber" impuesto a aquellos 5 .

\footnotetext{
${ }^{2}$ De conformidad con el artículo $2^{\circ}$ de la LBPA, su ámbito de aplicación se extiende a cualquier órgano perteneciente a la Administración, confiriéndoles amplias potestades de revisión para volver sobre sus actos administrativos por razones de legalidad o por motivos de oportunidad, conveniencia o mérito, en CORDERO Vega, 2015, p. 314 y Flores, 2017, p. 193.

${ }^{3}$ Lara y Guerrero, 2011, p. 19.

${ }^{4}$ Cordero Vega, 2015, p. 292.

5 Según el artículo 53 de la Ley 19.880, de 2003, los órganos administrativos tienen la facultad y, más aún, el deber de invalidar sus actos si se comprueba la existencia de vicios de legalidad que afecten esencialmente su contenido, pues se rigen por el principio de juridicidad, consagrado en los artículos $6^{\circ}$ y $7^{\circ}$ de la Constitución, de 1980 y $2^{\circ}$ de la Ley 18.575, de 1986. Véase dictámenes de la Contraloría General de la República, 20.05.2003, 020477N03; 28.09.2004,048799N04; 30.04.2015, 034598N15; 22.05.2017, 018543 N17, entre otros.
} 
En cuanto a sus efectos, se trata de una potestad que opera ex tunc, es decir, con efectos retroactivos desde el momento en que el acto administrativo antijurídico nace a la vida del derecho (ab initio), aunque dichos efectos se encuentran limitados a la existencia de situaciones jurídicas consolidadas de buena fe, generadas sobre la base de la confianza legítima de los particulares en la Administración ${ }^{6}$.

Recordemos que el ejercicio de la potestad de invalidación tiene por objeto la expulsión del acto administrativo del ordenamiento jurídico, debido a la pérdida de eficacia del mismo o de sus efectos por concurrir un vicio de ilegalidad, cuyo retiro, entonces, por parte de la Administración se justifica en la necesidad de resguardar el debido respeto y observancia del Derecho ${ }^{7}$.

b) La invalidación de sanciones administrativas: aspectos sustantivos y procedimentales

Tratándose de sanciones administrativas, será preciso establecer si el acto sancionatorio vulnera la normativa legal o reglamentaria que regula la materia respectiva o si incurre en alguna infracción al debido proceso, en cuyo caso será procedente la invalidación del acto sancionatorio. Además, de conformidad con lo previsto en los artículos 13 y 53 incisos $1^{\circ}$ y $2^{\circ}$ de la Ley 19.880 , el vicio invalidante deberá ser esencial y ocasionar perjuicio al infractor o afectar el interés general.

Así, por ejemplo, será procedente el ejercicio de la potestad invalidatoria si en el acto sancionador no se ha configurado el supuesto de hecho que da lugar a la infracción ${ }^{8}$; si el acto se ha dictado sin que los cargos hayan sido debidamente notificados al infractor; si en la tramitación del procedimiento sancionador no se ha concedido un plazo para la presentación de los descargos o en el caso que exista una disconformidad entre el supuesto de hecho y la infracción imputada al infractor?

El procedimiento de invalidación deberá ser practicado conforme con las reglas generales, esto es, de oficio o a petición de parte, debiendo instruirse previa audiencia del interesado, en la que se deberá considerar como "interesado" al infractor ${ }^{10}$. Además,

${ }^{6}$ Entre otros, véase los dictámenes de la Contraloría General de la República, 30.07.2009, 041190N09; 28.09.2010, 057284N10; 02.02.2011, 006518N11; 15.03.2013,016730N13; 14.08.2013, 051775N13.

${ }^{7}$ Sentencia de la Corte Suprema, 22.01.2019, rol 20.657-2018, c. $5^{\circ}$.

${ }^{8}$ En este sentido véase el dictamen de la Contraloría General de la República, 06.08.2008, 036717N08, en donde se sostuvo que la inobservancia del procedimiento especial allí señalado impide configurar la infracción imputada y la consiguiente multa.

${ }^{9} \mathrm{Al}$ efecto, la Contraloría General de la República ha señalado que corresponde invalidar la resolución que dejó sin efecto una sanción notificada al infractor una vez transcurrido el plazo legal establecido para tal efecto, lo anterior por cuanto los plazos no son fatales para la Administración y que a la data de emisión del acto aludido la infracción no se encontraba prescrita, en su dictamen de 27.07.2015, 059466N15.

${ }^{10}$ Ahora bien, en el caso que exista denunciante cualificado, y pese a que no se le puede considerar jurídicamente como parte interesada en el procedimiento sancionador, por razones de transparencia y publicidad, el órgano debiera notificar la realización de dicha audiencia. 
la potestad se deberá ejercer dentro de los dos años contados desde la fecha de notificación ${ }^{11}$ o publicación ${ }^{12}$ del acto que se trata de invalidar ${ }^{13}$.

Finalmente, el acto invalidatorio será siempre impugnable ante los tribunales de justicia por parte del infractor ${ }^{14}$, el que, si bien generalmente será favorecido con la declaración de invalidación del acto sancionatorio, puede ver afectados sus derechos en los casos de invalidación parcial. No obstante, el problema más complejo se puede presentar en los casos en que existan denunciantes calificados ${ }^{15}$.

\section{La revocación}

\section{a) Marco normativo general}

Este mecanismo está regulado en el artículo 61 de la LBPA, disposición que establece que los actos administrativos regulares y perfectos, podrán ser dejados sin efecto por el órgano que los hubiere dictado, salvo:

i) Que se trate de actos declarativos o creadores de derechos adquiridos legítimamente ${ }^{16}$;

ii) Que la ley haya determinado expresamente otra forma de extinción de los actos; o,

iii) Que por su naturaleza, la regulación legal del acto impida que sean dejados sin efecto.

La facultad de revisión de oficio se distingue de la potestad de invalidación en que, siendo ambas causales de retiro de actos administrativos y de extinción -total o parcial-de

${ }^{11}$ Si se trata de un acto administrativo de efectos particulares, artículo 45 de la Ley 19.880 de 2003.

${ }^{12}$ Si se trata de un acto administrativo de efectos generales, artículo 48 de la Ley 19.880, 2003.

${ }^{13}$ Recordemos que se trata de un plazo de caducidad y no de prescripción, toda vez que la potestad de invalidación se agota con el hecho objetivo del transcurso del tiempo, sin que se pueda alegar o invocar la existencia de causales de suspensión o interrupción del plazo. De este modo, si la autoridad administrativa desea que el acto quede sin efecto por razones de legalidad (transcurrido el plazo de dos años), entonces la acción debe ser ejercida ante el juez, vid. CORDERo VEGA, 2015.

${ }^{14}$ Ello de conformidad al principio de impugnabilidad reconocido en el artículo 15 de la Ley 19.880, de 2003 y en el artículo 10 de la Ley 18.575, de 1986, en procedimiento breve y sumario, es decir, conforme con los artículos 680 y siguientes del Código de Procedimiento Civil.

${ }^{15}$ En este punto, es razonable tener presente que por regla general el denunciante no forma parte del procedimiento sancionador como interesado, ya que carece de una suerte de "derecho a castigar", en conciencia, su rol es la de un simple denunciante, que actúa como colaborador de la Administración. Sin embargo, puede darse la figura del denunciante calificado, esto es, que se trate de una víctima de la infracción denunciada, en cuyo caso, y como titular de un derecho afectado, podría efectuar alguna alegación jurisdiccional. Al efecto véase Gómez (en prensas).

16 Dentro de los límites al ejercicio por parte de la Administración de la revocación destaca la imposibilidad de ejercer la facultad revocatoria cuando se trata de " [...] actos de contenido favorable, los que no pueden ser dejados sin efecto por la autoridad administrativa por razones de oportunidad o conveniencia -revocación- y que solo pueden serlo por razones de ilegalidad - invalidación-”, véase sentencia de la Corte Suprema, 29.10.2007, rol 4.800-2007. 
sus efectos jurídicos, la revocación supone la facultad de la Administración de volver sobre sus propios actos, con el fin de verificar la oportunidad y conformidad de ellos con el ordenamiento jurídico, así como su conveniencia en términos de interés general.

La revocación consiste en la retirada un acto administrativo válido del ordenamiento jurídico ${ }^{17}$, el que es dejado sin efecto por la propia autoridad emisora del mismo mediante un acto de contrario imperio, en consideración a que vulnera el interés público general o específico de la autoridad que lo ha emitido - esto es, por razones de justicia y no de legalidad-, decisión que, por esta razón, y a diferencia de la invalidación, se funda en razones de mérito, conveniencia u oportunidad ${ }^{18}$.

Por su parte, la Corte Suprema ha señalado que la potestad revocatoria es de exclusiva y discrecional competencia de la Administración, y que tiene por objeto eliminar los efectos inconvenientes o inoportunos de un acto administrativo ${ }^{19}$.

En suma, para la doctrina la potestad revocatoria origina una tensión entre, por una parte, el interés público que exige la modificación de una situación jurídica existente y, por la otra, la seguridad jurídica del particular respecto de la mantención de su statu quo intangible, derivado de la regularidad jurídica del acto administrativo que se pretende revocar ${ }^{20}$.

\section{b) La revocación de las sanciones administrativas}

Tratándose de sanciones administrativas, la procedencia de la revocación resulta discutible. Por una parte, la doctrina sostiene que una sanción no puede ser dejada sin efecto por razones de mérito, oportunidad o conveniencia, ya que verificada la infracción y la responsabilidad del infractor la autoridad está en el imperativo de sancionar y ejecutar la medida impuesta ${ }^{21}$. La clasificación de la sanción administrativa como acto de gravamen no permite entender que la Administración pueda en cualquier momento proceder a su revocación, ya que con ello se desconocería la naturaleza de la actividad

${ }^{17}$ En efecto, mediante la revocación se busca extinguir los efectos de un acto administrativo válido, pero inconveniente e inoportuno con el actual interés general. En otras palabras, la revocación será procedente en la medida que el concepto de interés general ha sido objeto de un cambio de apreciación sobreviniente, lo que genera que el nuevo concepto de "interés general" contravenga el objeto mismo del acto administrativo cuya revocación se pretende, en FLORES, 2017, pp. 218 y 219.

${ }^{18}$ Dictámenes de la Contraloría General de la República, 22.11.1966, 089271N66; 22.03.1979, 016211N79; 14.11.1991, 027386N91; 28.01.1993, 002196N93; 05.01.1994, 000199N94; 23.05.1995, 015553N95; 15.01.1997, 001710N97; 30.01.2004, 004614N04; 19.01.2005, 002641N05; 18.02.2009, 008058N09; 20.05.2014, 035081N14; 27.07.2015, 059466N15; 04.12.2015, 096610N15; 02.02.2017, $003590 \mathrm{~N} 17$; entre otros.

En doctrina, véase a Cordero Vega, 2015, pp. 314 y ss.

${ }^{19}$ Corte Suprema, 29.07.2011, rol 6.379-2011.

${ }^{20}$ Flores, 2017, p. 198.

${ }^{21}$ En este sentido, Cordero Vega, 2015, p. 315.

Por su parte, Alejandro Nieto ha señalado que " [...] impuesta una sanción no sería lícita su revocación de oficio sin formalidad alguna alegando que se trata de un acto de gravamen no sujeto a los trámites legales específicos de tal revocación. O más exactamente todavía: la revocación es admisible si se constata 
sancionadora, la que presupone la comisión de una infracción o conducta antijurídica del destinatario de la sanción, lo que impide sostener que está limitando su derecho ${ }^{22}$. Además, su aplicación afectaría gravemente el principio de igualdad garantizado constitucionalmente (artículo $19 \mathrm{~N}^{\circ} 2$ ) $^{23}$. Lo que sí sería procedente es que la autoridad pueda hacerlo por razones de legalidad mediante el ejercicio de la potestad invalidatoria, en la medida que nos encontremos con un acto sancionador que sea contrario a derecho ${ }^{24}$. Así, por ejemplo, la sanción podría ser invalidada si en su aplicación se ha afectado el principio de proporcionalidad o alguna garantía procedimental.

En tanto, para otros autores sería plenamente procedente, atendida la doble naturaleza de acto administrativo/acto de carácter desfavorable o gravoso ${ }^{25}$, ello en la medida que la ley no disponga como un deber para la Administración el exigir la ejecución de la sanción ${ }^{26}$. Para esta doctrina, el carácter general de la revocación como mecanismo de revisión de los actos administrativos le permite a la Administración dejar sin efecto una sanción impuesta por el propio órgano que la emitió ${ }^{27}$.

Ahora bien, quienes sostienen esta tesis realizan un llamado a adoptar fuertes precauciones en su ejercicio, para evitar que la Administración pueda dejar sin efecto sanciones basadas en motivaciones subjetivas e incluso de discutible legalidad, siendo preciso evitar una eventual desviación de poder $^{28}$. En definitiva, la revocación de sanciones, por

que la sanción fue indebidamente impuesta; no siendo admisible, en cambio, si su imposición fue correcta", Nieto, 2012, p. 101.

No obstante, es razonable tener presente que, en España, la revocación como institución tiene una regulación diversa a la asignada en el orden jurídico nacional. Según la doctrina, el artículo 109, de la Ley 39/2015, sería comprensiva de una revocación por: a) motivos de legalidad, esto es, retirada de actos viciados y b) de oportunidad, que corresponde a la retirada de actos perfectamente regulares, pero inconvenientes en un momento dado, al efecto véase a Parejo, 2013, p. 489.

22 PARADA, 1989, p. 285.

23 En este sentido, véase el artículo 109 de la Ley 39/2015, de 1 de octubre, del Procedimiento Administrativo Común de las Administraciones Públicas de España.

${ }^{24}$ Cordero, 2014, pp. 336 y 337.

${ }^{25}$ Según lo indica Villar Palasí, el carácter gravoso del acto sancionatorio [multa] tiene como consecuencia su revocabilidad, en Villar Palasí, 1955, p. 29. En este mismo sentido Sanz Rubiales ha señalado que "La doble caracterización de las sanciones administrativas -actos administrativos, por una parte, y manifestaciones del ius puniendi, por otra- incide en la aplicabilidad del principio general de revocabilidad de los actos de gravamen o desfavorables”, en SAnz Rubiales, 1999, p. 385, y Huergo Lora, 2007, pp. 441 y ss. Por su parte, en el Derecho peruano, Morón Urbina señala que la revocación, regulada en el artículo 203.1 de la Ley de Procedimiento Administrativo General, se establece para privilegiar la seguridad jurídica del titular de actos declarativos o constitutivos de derechos o intereses legítimos y, por tanto, no puede hacerse extensivo a los actos administrativos que no son favorables a los administrados ya que estos son los gravosos o aquellos que de cara al ciudadano son neutros, en Morón Urbina, 2011, pp. 431 y ss.

Asimismo, Bocanegra critica la distinción entre actos favorables o declarativos de derechos y actos desfavorables o de gravamen en términos lineales, lo que en su opinión sería un error porque, si bien un acto puede ser calificado en mayor parte como favorable, puede tener aspectos desfavorables, ocurriendo lo mismo a la inversa, al efecto véase a BocaneGra, 1977, p. 256.

${ }^{26}$ Ortega, 2015, p. 160

27 CANO, 2018, p. 203.

${ }^{28}$ En este sentido, Sanz Rubiales, 1999, p. 385 y García de Enterría y Fernández, 2011, p. 689. 
ser su ejercicio difícil de controlar desde el punto de vista jurídico, debe interpretarse restrictivamente, sometiéndose a diversos requisitos, tanto materiales como formales, para salvaguardar la integridad del ordenamiento y los derechos de los administrados ${ }^{29}$.

Por su parte, según la doctrina nacional, en nuestro ordenamiento el problema tiene su origen en la forma en la que ha sido regulado el estatuto de la revocación administrativa, porque no se precisa la procedencia, límites y alcances de la potestad revocatoria sobre los actos administrativos desfavorables o perjudiciales para los particulares ${ }^{30}$. En este sentido, Flores considera que no sería suficiente para sostener la vigencia de la potestad revocatoria respecto de los actos de gravamen una interpretación garantista del artículo 61 de la LBPA, máxime cuando al ejercer dicha potestad la Administración podría perjudicar los derechos o intereses de terceros, e infringir la regla constitucional de la igualdad y proscripción de discriminaciones arbitrarias. Por tanto, para dicho autor, cada vez que la Administración pretenda revocar un acto de gravamen es preciso que su ejercicio se ampare en un fundamento más sólido que la mera interpretación a contrario sensu del aludido artículo 61, debido a las fuertes exigencias del principio de legalidad en materia de actos de gravámenes, principalmente frente a actos sancionadores ${ }^{31}$.

En armonía con lo sostenido por dicho autor, de admitirse la revocación de sanciones administrativas, será un imperativo para la respectiva autoridad motivar debidamente el acto revocatorio, no siendo suficiente argumento la habilitación general que proporciona el referido artículo 61. Al efecto, es apropiado tener presente que el ejercicio de esa potestad, que la ley ha configurado como discrecional, no implica la posibilidad de ejercicio arbitrario, sino que ha de ejercerse cuando lo requiera el interés público que la ley le permite apreciar a la Administración caso a caso. De este modo, resulta necesaria una justificación suficiente de la decisión desde el punto de vista del interés público, que actúe como salvaguarda de los principios que limitan el ejercicio de la revocación, fundamentalmente el principio de igualdad.

Por ello, la revocación de sanciones debe responder a una adecuada motivación, que dé cuenta de las razones que ha tenido la autoridad para adoptar la medida, garantizando así la transparencia de las decisiones administrativas y la interdicción de la arbitrariedad, además de operar bajo determinados parámetros o límites ${ }^{32}$.

Junto con lo anterior, no se puede obviar el hecho de que la revocación se encuentra limitada por la consumación de los efectos del acto y por la existencia de derechos adquiridos $^{33}$. Además, su aplicación respecto de actos administrativos sancionatorios debiera ser excepcional, buscando siempre resguardar los derechos de los afectados por la infracción, así como también los del sujeto infractor, de forma que su ejercicio se

\footnotetext{
${ }^{29}$ Sanz Rubiales, 1999, p. 359.

${ }^{30}$ Flores, 2017, pp. 209 y 215 y ss.

31 Flores, 2017, pp. 216.

32 García-Trevijano, 1996, pp. 420 y ss.

33 Aunque difícilmente de la aplicación de una sanción podrán surgir derechos subjetivos, en este caso, más bien corresponde hacer referencia a los derechos o intereses legítimos que se dejaron de afectar con la aplicación de la sanción, al efecto véase a TOLA RúA, 1999, pp. 852 y ss.
} 
condicione o subordine, por ejemplo, a la satisfacción de las responsabilidades civiles o patrimoniales que hayan podido derivarse de la conducta infractora o, al menos, a la manifestación de una voluntad inequívoca en tal sentido.

Por último, y a diferencia de la invalidación que produce efectos ex tunc, la revocación no elimina las otras consecuencias que derivan del acto sancionatorio revocado, ya que sus efectos son ex nunc o profuturo, de manera que no desparecen las responsabilidades civiles o penales, las medidas accesorias decretadas o la ocurrencia del ilícito mismo, lo que podrá ser considerado en otro procedimiento sancionador como reincidencia ${ }^{34}$.

\section{c) La revocación de sanciones en la jurisprudencia administrativa y su aplicación por los órganos públicos}

Acerca del particular, nuestra jurisprudencia administrativa ha emitido diversos pronunciamientos. Al efecto, de manera previa a la dictación de la LBPA, la Contraloría General de la República sostuvo que los actos que imponen sanciones son irrevocables cuando están totalmente tramitados, porque constituyen actos terminales de un proceso reglado, el que una vez concluido produce el desasimiento de la autoridad administrativa que impuso la medida ${ }^{35}$. Para dicho órgano, permitir la modificación de las decisiones (aunque refiriéndose a las materias disciplinarias) mediante una nueva ponderación de los hechos con un criterio distinto o por razones de mérito, alteraría la permanencia de las mismas ${ }^{36}$.

Por su parte, en un pronunciamiento relativamente reciente, ha señalado que no procede la revocación en aquellos casos en que la normativa sectorial contemple mecanismos especiales para la extinción de las sanciones, como la condonación ${ }^{37}$. Agrega que, para su ejercicio en aquellos casos, la autoridad deberá tener en especial consideración que la

${ }^{34}$ En este sentido, por ejemplo, el artículo 21.6. de la Ley 2/1998, de 20 de febrero, de la potestad sancionadora de las Administraciones Públicas de la Comunidad Autónoma del País Vasco señala que el indulto y la conmutación de sanciones no comprenderán ni afectarán las responsabilidades civiles que pudieran derivarse de la conducta infractora, ni a las obligaciones de reparación e indemnización reguladas en dicha ley.

${ }^{35}$ Vid. Dictamen de la Contraloría General de la República, 18.08.1971, 057317N71.

36 Dictamen de la Contraloría General de la República, 02.08.2005, 035868N05. Ahora bien, en dictámenes posteriores y en el mismo ámbito disciplinario, el órgano contralor ha señalado que "[ [...] la autoridad que haya resuelto una reposición -o una apelación si fuere ésta la última instancia de impugnación de la sanción-, se encuentra facultada para revisar de oficio y revocar la decisión previamente adoptada, independientemente si ésta ha sido notificada o no a su destinatario, siempre que existan razones de mérito, conveniencia u oportunidad que así lo determinen, toda vez que, mientras la sanción no se materialice en un acto administrativo afecto y éste se encuentre totalmente tramitado, dicho castigo no habrá adquirido plena vigencia jurídica y, por tanto, es susceptible de ser modificado por la superioridad, sea disminuyéndolo o aumentándolo”, en dictamen de la Contraloría General de la República, 10.12.2010, 074035N10.

${ }^{37} \mathrm{La}$ jurisprudencia administrativa ha señalado que si la ley ha regulado en forma expresa otras formas de extinción de tales actos administrativos, procede señalar que a su respecto concurre el supuesto establecido en el artículo 61, inciso segundo, letra b), de la LBPA, por lo que resulta improcedente disponer su revocación, véase dictamen de la Contraloría General de la República, 27.07.2015, 059466N15. Este criterio fue recogido por la Dirección del Trabajo en la Orden de Servicio No 2, de 19 de abril de 2016 (p. 3 ). 
potestad sancionadora, en cuanto manifestación del ius puniendi del Estado, constituye el reproche que, en pos del bien común que debe cautelar, dicho organismo efectúa al infractor de la legislación respectiva, de modo que, en la supervivencia o supresión del acto administrativo dictado en su ejercicio, se encuentra comprometido el interés general de la comunidad ${ }^{38}$.

A nivel sectorial, existen servicios que, si bien no han aplicado la revocación, tampoco descartan su procedencia. En tanto, hay casos en los que algunos órganos han ejercido la facultad, pero, en la práctica, se trata de invalidaciones parciales por vicios de procedimiento ${ }^{39}$.

d) Requisitos sustantivos y procedimentales para la revocación de sanciones administrativas

En el ámbito sustantivo, por regla general, la revocación de sanciones administrativas será procedente en la medida que, de las circunstancias del caso concreto, se aprecie que la respuesta punitiva, aun cuando se encuentre conforme con la legalidad vigente, no resulta adecuada a lo que la equidad, la justicia o el interés general propugnan en el caso concreto, y siempre que no exista otra vía o mecanismo legal para lograr el fin que por medio de la revocación se pretende obtener ${ }^{40}$ o en aquellos casos en los que la naturaleza de la regulación legal impida que el acto sea dejado sin efecto ${ }^{41}$.

Enseguida, el ejercicio de la potestad revocatoria en materia de sanciones administrativas debe observar el principio de proporcionalidad, siendo especialmente relevante que para su adopción la autoridad tenga en consideración la gravedad de la infracción cometida, el quantum de la sanción, los efectos del ilícito y, en su caso, las medidas adoptadas por el infractor para mitigar sus consecuencias, entre otros criterios.

38 Véase dictamen de la Contraloría General de la República, 27.07.2015, 059466N15. A nivel comparado, se ha aceptado que la existencia de un interés legítimo y personal en velar por el correcto ejercicio de la potestad administrativa permitiría impugnar el acto que dispone la revocación de una sanción. Así, el Tribunal Constitucional español sostuvo que "[...] resulta evidente que una asociación con fines de defensa de la naturaleza y del mundo animal tiene un interés legítimo y personal en velar por el correcto ejercicio de la potestad administrativa, en este caso respecto de la revocación de la sanción impuesta a un cazador que había abatido una avutarda.”, en sentencia del Tribunal Constitucional Español, 31.01.1994, rol 34/1994, sala 2a , F.J. 3.

39 Véase Resolución Exenta D.J. N 111-077-2017, de la Unidad de Análisis Financiero, recaída en el procedimiento sancionatorio Rol No 002-2016, conforme con ello se revocó la resolución exenta que allí se indica y se fijó día y hora para rendición de prueba testimonial. En este caso, mediante la revocación se buscó corregir vicios de carácter procedimental, los que debieron ser subsanados con una invalidación parcial.

${ }^{40}$ En aquellos casos en que la ley ha dispuesto de la condonación como mecanismo de extinción de los efectos de las sanciones. Al efecto véase los dictámenes precedentemente analizados.

${ }^{41}$ Para la aplicación de esta causal, la Contraloría ha señalado que, al no existir norma legal en contrario, no resulta aplicable respecto de ellos la excepción contemplada en la letra c) del citado artículo 61, véase dictamen de la Contraloría General de la República, 19.01.2005, 002641N05. 
En cuanto a los aspectos procedimentales, es preciso tener en consideración, en primer lugar, que la sanción solo puede ser revocada por la propia autoridad que la dictó $^{42}$. Enseguida, si bien la ley omitió establecer las reglas mínimas para la tramitación del procedimiento revocatorio ${ }^{43}$, sería pertinente que tratándose de la revocación de sanciones administrativas se dispusiera de la realización de una audiencia previa que permitiera al sujeto infractor $y$, en su caso, a los denunciantes cualificados, manifestar lo que estimen pertinente en relación con la conveniencia en la mantención del acto administrativo válido que se pretende revocar ${ }^{44}$. Ahora bien, esta regla pudiera ser omitida tratándose de sanciones leves o en aquellos casos en que no existan denunciantes, de lo que deberá quedar expresa motivación en el acto revocatorio. Adicionalmente, y conforme con las disposiciones respecto de publicidad y transparencia de la actividad administrativa, será necesario practicar, junto con la notificación al sancionado y demás interesados, la publicación en el sitio web del servicio de que se trate la resolución que dio lugar a la revocación del acto sancionatorio.

Es acertado precisar que la revocación podrá recaer sobre todas o alguna de las sanciones impuestas al infractor o sus consecuencias accesorias, ello únicamente en la parte que se encuentre pendiente de cumplimiento, sin que sea procedente la devolución de sumas ya enteradas por dicho concepto o por el pago de indemnizaciones de los daños que los efectos de la medida hubieran generado en el tiempo anterior a la dictación del acto revocatorio.

Por último, y de conformidad con las reglas generales, la iniciación del procedimiento revocatorio no suspenderá la ejecutividad de la sanción, salvo que mediare una orden de suspensión dispuesta por la autoridad administrativa, a petición fundada del infractor, especialmente en aquellos supuestos en los que la ejecución de la sanción pudiere causar daño irreparable o hacer imposible el cumplimiento de lo que se resolviere, en caso de acogerse la revocación ${ }^{45}$. Por su parte, la solicitud de revocación del acto sancionatorio interrumpirá el plazo de prescripción de aquella.

\section{El decaimiento del acto administrativo sancionatorio}

En tercer lugar, y como otro mecanismo general de revisión del acto sancionatorio, es admisible señalar el "decaimiento del acto administrativo". En Chile esta teoría ha sido principalmente invocada por la jurisprudencia judicial para dejar sin efecto sanciones impuestas en procedimientos que han sido tramitados fuera de un plazo razonable,

42 Artículo 61 Ley 19.880, de 2003 y Flores, 2017, pp. 201 y 202.

${ }^{43}$ Flores, 2017, p. 209.

${ }^{44}$ En este sentido, el artículo 21.2 letras c) y d) de la Ley 2/1998, de 20 de febrero, que establece la potestad sancionadora de las Administraciones Públicas de la Comunidad Autónoma del País Vasco (en adelante, LPSPV), establece como trámites esenciales dentro del procedimiento de indulto y conmutación de sanciones administrativas, las alegaciones tanto de la persona sancionada como también de las partes en el procedimiento sancionador de que se trate.

45 Artículos $3^{\circ}$ inciso final y 57 de la LBPA. 
dilación indebida e injustificada que, según lo afirman los tribunales, vulnera los principios de eficiencia, eficacia y celeridad, los que se relacionan con la oportunidad en que se deben realizar las actuaciones administrativas ${ }^{46}$.

Asimismo, la jurisprudencia ha señalado que la finalidad preventivo-represora del acto administrativo sancionatorio se torna inútil producto del excesivo tiempo transcurrido. En efecto, por medio de la sanción se persigue el desaliento de futuras conductas ilícitas similares, se busca reprimir la conducta contraria a derecho y restablecer el orden jurídico previamente quebrantado por la acción del transgresor ${ }^{47}$.

Según lo expone la Corte Suprema, bajo tal contexto la aplicación de una sanción importa la vulneración de las garantías de igualdad ante la ley y de trato que debe observar la autoridad administrativa (artículo $19 \mathrm{~N}^{\circ} 2 \mathrm{CRP}$ ), ya que resuelve fuera de todo plazo razonable, tornando su determinación en discriminatoria. Además, se afecta la garantía del derecho de propiedad, porque se mantiene amenazado ilegítimamente al infractor con la aplicación de una sanción (artículo $\left.19 \mathrm{~N}^{\mathrm{o}} 24\right)^{48}$.

Ahora bien, para la literatura clásica el acto administrativo decae cuando desaparecen los presupuestos de hecho o de derecho que motivaron su dictación o porque se hace inutilizable. En estas circunstancias, el decaimiento produce la inexistencia sobreviniente de los efectos del acto, pues este, a lo menos desde el punto de vista formal, continuaría vigente $^{49}$. De esta manera, el decaimiento de un acto administrativo se puede producir por: a) la desaparición de un presupuesto de hecho indispensable para la validez del acto; b) la derogación de la regla legal en que se funda el acto, cuando dicha regla era condición indispensable para su vigencia; o c) la modificación del régimen legal que constituya un impedimento para el mantenimiento del acto ${ }^{50}$.

En atención a estas características, la doctrina nacional se ha mostrado crítica a la aplicación de la teoría del decaimiento tratándose de dilación excesiva en los procedimientos sancionatorios debido a que se trata: a) de un problema que se da al interior del procedimiento administrativo sancionador, sin que exista un acto administrativo terminal; y b) no se ha suscitado ninguna circunstancia sobreviniente que acarree la ilegitimidad jurídica del acto ${ }^{51}$.

En efecto, el decaimiento procede respecto del acto y no del procedimiento. En este punto, cabe tener presente que la infracción a los plazos de tramitación del procedimiento

\footnotetext{
${ }^{46}$ Doctrina que surge en el ámbito sancionatorio eléctrico como respuesta a la excesiva demora en la resolución de los procedimientos represivos tramitados por la Superintendencia de Electricidad y Combustibles (SEC), Vid. Corte Suprema, 28.01.10, rol 7.284-2009; 28.01.2010, 7.502-2009; 16.09.2010, rol 4.9232010; 15.09.2010, rol 4.922-2010; 04.01.2013, rol 5.228-2010; entre otras.

Por su parte, en doctrina se puede consultar: BoCKSANG, 2011, pp. 225-252; Cordero, 2011, pp. 243-255; Evans y Poblete, 2014, pp. 217-237; Valdivia y Blake, 2015, pp. 93-135, entre otros.

${ }^{47}$ Corte Suprema, 03.08.2017, rol 38.340-2016.

${ }^{48}$ Corte Suprema, 26.07.2017, rol 11.552-2017, c. $7^{\circ}$.

49 Cordero Vega, 2011, p. 245.

50 Cordero Vega, 2011, p. 246.

${ }^{51}$ No hay pérdida de objeto, no se han alterado los supuestos de hecho ni se han producido modificaciones legales sustantivas que afecten los efectos del acto, Cordero Vega, 2011, p. 254.
} 
administrativo, salvo los términos contemplados en leyes especiales, ha sido regulada en el artículo 27 de la Ley 19.880, precepto que señala que, salvo caso fortuito o fuerza mayor, el procedimiento administrativo no podrá exceder de 6 meses desde su iniciación hasta la fecha en que se emita la decisión final, norma que sin embargo ha sido matizada por una reiterada jurisprudencia ${ }^{52}$, privándola de todo efecto preclusivo. De esta manera, resulta una impropiedad hablar del decaimiento del procedimiento administrativo, en circunstancias que se trata del decaimiento del acto administrativo.

Expuesto lo anterior, el decaimiento del acto sancionatorio se encuentra vinculado con sucesos posteriores a la dictación del acto sancionador perfectamente válido, cuya concurrencia genera que sus efectos desaparezcan. Ello puede ocurrir, por ejemplo, en caso de muerte de la persona natural (tratándose de sanciones no pecuniarias ${ }^{53}$ ), con la derogación del régimen sancionador que justificó la imposición de la medida, o bien con supresión del servicio público que aplicó la sanción sin que exista un sucesor legal del mismo.

\section{Mecanismos de Revisión especiales}

No obstante la existencia de mecanismos generales de revisión de la sanción administrativa, el ordenamiento jurídico ha dispuesto a nivel sectorial de diversos medios para la extinción de la sanción, sea por medio de la extinción definitiva de la misma o mediante su reemplazo por otra medida.

En este contexto podemos encontrar la condonación, la suspensión y la sustitución de las sanciones impuestas.

\section{La condonación}

\section{a) Concepto}

La condonación es definida como una forma de extinción de la responsabilidad administrativa consistente en el indulto o perdón del cumplimiento de una sanción legalmente impuesta por razones de equidad o para garantizar un interés general ${ }^{54}$. Para la doctrina nacional, la "condonación", se refiere a la remisión, total o parcial, de

52 Conforme con ello, salvo disposición legal en contrario, los plazos no son fatales para la Administración, ni su vencimiento implica caducidad o invalidación del acto de que se trate, ya que solo tienen por objeto establecer un buen orden administrativo para dar cumplimiento a las funciones de sus órganos, véase dictámenes de la Contraloría General de la República, 03.04.2009, 017388N09; 08.01.2010, 000957N10; 27.09.2011, 061059N11; 02.10.2012, 060718N12; 22.11.2013,076788N13; y 27.07.2015, 059466N15; entre otros.

53 Tratándose de sanciones pecuniarias la jurisprudencia judicial ha señalado que, si la muerte del infractor se ha producido una vez dictado y notificado válidamente el acto administrativo sancionador, sus efectos patrimoniales se transmiten a los herederos del infractor, en Corte Suprema, 30.10.2014, rol 11.079-2014, c. $11^{\circ}$.

${ }^{54}$ Lozano, 1990, p. 180 y MuÑoz Machado, 2017, p. 540. 
la deuda que el órgano administrativo realiza conforme con sus facultades, la que no importa la extinción de la responsabilidad administrativa, sino que se trata de un modo de extinguir la obligación de pago de la multa que de ella proviene ${ }^{55}$.

\section{b) Naturaleza, características y regulación}

Si bien la condonación no tiene una regulación general ${ }^{56}$, existen leyes especiales que contemplan expresamente dicha posibilidad. Se trata de una institución de carácter excepcional que exonera al infractor del cumplimiento de la sanción de que se trate, operando mediante la inejecución de la medida ${ }^{57}$. La condonación encuentra su justificación en la necesidad de permitir al órgano sancionador evaluar las circunstancias concurrentes en la infracción frente al automatismo con el que operan la imposición de las sanciones administrativas $^{58}$, se trata de la apreciación a posteriori de circunstancias que modifican la responsabilidad infraccional ${ }^{59}$, que alteran el contenido y efectos de la sanción impuesta.

La condonación es una potestad esencialmente discrecional en cuanto a la oportunidad y extensión del beneficio ${ }^{60}$, sin que constituya un derecho para el infractor que la solicita ${ }^{61}$.

Para la doctrina, este mecanismo únicamente puede ser ejercitado en el caso de que esté expresamente previsto por las leyes sectoriales, con las específicas limitaciones que allí se señalen ${ }^{62}$. Esta exigencia tendría su fundamento en los principios de legalidad, equidad e igualdad ${ }^{63}$, los que tienen por objeto impedir que la Administración actúe arbitrariamente estableciendo la forma y requisitos en los que la autoridad podrá aplicar las medidas de gracia a los sujetos infractores.

Al igual que la revocación, la condonación se debe solicitar al órgano que emitió el acto sancionatorio ${ }^{64}$ y el acto que así la declare podrá ser objeto de una posterior

55 Osorio, 2016, p. 518.

${ }^{56}$ En España, tampoco se encuentra regulada la condonación con carácter general. Ahora bien, a nivel comunitario, la LPSPV, la regula expresamente y con un alto grado de detalle en sus artículos 20 y 21.

${ }^{57}$ La condonación actúa sobre la sanción impuesta para reducir o exceptuar su aplicación, en DANós, 2014 , p. 31.

58 LoZANO, 1990, p. 193.

59 GonzÁlez PÉrez, 1983 , p. 858.

${ }^{60}$ LOZANO, 1990, pp. 185 y 186.

61 Vid. Sobrao Martínez, 1978, p. 802.

62 Zanobini, 1958, p. 357; GonZÁlez Pérez, 1972, pp. 83 y ss.; SANZ Rubiales, 1999, p. 385 y en LASAGABASTER, 2010, p. 153, este último autor, por una parte, no considera que la condonación corresponda a una facultad discrecional y, por la otra, descarta la posibilidad de que la Administración pueda disponer la condonación de una sanción en ausencia de un texto expreso.

Por su parte, el Tribunal Supremo español ha señalado que motivos de equidad y justicia no puede amparar el supuesto derecho a que la Administración condone dichas medidas sin que aquella potestad esté prevista en la normativa aplicable como una causal de extinción de la responsabilidad, vid. Tribunal Supremo español, Recurso No 328/1991, sentencia de 18 de abril de 1994, fundamento jurídico $3^{\circ}$.

63 Danós, 2014 , p. 31.

${ }^{64}$ Dictamen de la Contraloría General de la República, 19.08.2014, 063527N14. 
revisión jurisdiccional ${ }^{65}$. Por su parte, por regla general, la legislación sectorial autoriza al órgano a que el acto que declare la condonación de la sanción pueda extinguir total o parcialmente la responsabilidad administrativa.

Finalmente, es preciso señalar que si bien la condonación es una figura que se vincula a sanciones de tipo pecuniario, sería perfectamente posible establecerla respecto de sanciones de naturaleza diversa.

\section{c) Algunos casos de regulación sectorial de la condonación}

Así sucede, por ejemplo, con las sanciones tributarias, en donde el artículo 6 letra b) $\mathrm{N}^{\circ} 3$ del Código Tributario señala que los Directores Regionales del Servicio de Impuestos Internos podrán condonar las sanciones administrativas fijas o variables ${ }^{66}$.

Por su parte, el inciso final del artículo 64, del D.F.L. N $^{\circ} 3$, de 1997, que fija el texto refundido, sistematizado y concordado de la Ley General de Bancos y de otros cuerpos legales que se indican, establece que: "Si la falta de encaje se originare por causa de cierre bancario y no se prolongare por más de 15 días contados desde la fecha de cesación del cierre, el Superintendente podrá rebajar o condonar la multa”.

Asimismo, del inciso final del artículo 22 letra a) de la Ley 17.322, de 1970, que establece las normas para la cobranza judicial de cotizaciones, aportes y multas de las instituciones de seguridad social, se desprende que la regla general es la condonación de las multas impuestas, salvo en los supuestos que allí se indican. En este sentido, la Contraloría ha señalado que las aludidas instituciones tienen la prohibición expresa de condonar las multas a los empleadores que no hayan declarado oportunamente las sumas que adeudan por concepto de imposiciones y también a los que hubieren efectuado declaraciones maliciosamente incompletas o falsas. Por el contrario, sí puede practicar la aludida condonación respecto de los deudores cuya declaración sea oportuna, veraz y completa ${ }^{67}$.

Por su parte, el artículo 128 inciso segundo parte final de la Ordenanza General de Aduanas establece que en la o las audiencias de conciliación que se lleven a cabo, el Servicio podrá proponer la condonación total o parcial de las multas aplicadas, conforme

${ }^{65}$ LozAno, 1990 , pp. 185 y 186. Para la autora la condonación por motivos que no respondan a la finalidad de justicia y equidad o que su otorgamiento sea notoriamente desproporcionado con el fin de justicia que lo motiva, pueden considerarse como supuestos de desviación de poder controlables en la vía administrativa y judicial.

${ }^{66}$ Mediante circulares, el servicio ha establecido la "condonación automática de multas e intereses" bajo la concurrencia de ciertos supuestos, quedando su discrecionalidad regulada por parámetros objetivos. Opera de manera inmediata al efectuar el pago en línea; vale decir, el contribuyente solo debe declarar mediante la Oficina Virtual del SII y automáticamente le será calculada la condonación (siempre que no tenga observación pendiente de aclaración). Este sistema está regulado en sus Circulares $\mathrm{N}^{\text {os }} 1$, de 2004,21 y 41, ambas de 2013. Asimismo, el SII ha dispuesto a condonación bajo ciertos supuestos, como aconteció recientemente por medio de la resolución exenta $\mathrm{N}^{\circ} 32$, de 21 de marzo de 2018, mediante esta se otorgó la condonación respecto de las multas infraccionales en los casos que allí se señalan.

${ }^{67}$ Dictámenes de la Contraloría General de la República, 28.07.2015, 059913N15; y 03.01.2019, 003259 N19. 
con los criterios generales que fije mediante resolución, los que a la data no se encuentran regulados por dicho Servicio ${ }^{68}$.

Finalmente, el artículo $3^{\circ}$ letra d) de la Ley 16.282, de 1965, que fija disposiciones permanentes para casos de sismos o catástrofe, autoriza al Presidente de la República para que, mediante decreto supremo fundado, dicte normas de excepción destinadas a resolver los problemas de las localidades declaradas como zonas dañadas por la catástrofe, en las situaciones que taxativamente describe, lo que considera la posibilidad de otorgar autorizaciones a los organismos correspondientes para que puedan condonar parcial o totalmente los intereses penales, multas y sanciones, pudiendo también fijar nueva fecha de pago o prórrogas ${ }^{69}$.

\section{La suspensión de la sanción}

Por regla general, los actos administrativos gozan de una presunción de legalidad, de imperio y exigibilidad frente a sus destinatarios, desde su entrada en vigor, autorizando su ejecución de oficio por la autoridad administrativa, salvo que mediare una orden de suspensión dispuesta por la autoridad administrativa dentro del procedimiento impugnatorio o por el juez, conociendo por la vía jurisdiccional (artículo $3^{\circ}$ inciso final de la LBPA). De esta manera, la interposición de los recursos administrativos no suspenderá la ejecución del acto impugnado, a menos que su cumplimiento pudiere causar daño irreparable o hacer imposible el cumplimiento de lo que se resolviere, en caso de acogerse el recurso (artículo 57 LBPA) o en los casos que la ley lo señale expresamente, como ocurre en materia de mercado financiero ${ }^{70}$.

En estos casos, la suspensión solo tiene por objeto paralizar temporalmente la eficacia de la sanción impuesta, de modo que, una vez resueltos los recursos respectivos, esta se ejecutará ${ }^{71}$. Ahora bien, si la suspensión no es decretada es posible la exigibilidad de la sanción y además comienza a correr el plazo de prescripción de la medida impuesta ${ }^{72}$.

68 Según se ha indicado en oficio ordinario No 2405, de 2019, del Servicio Nacional de Aduanas, en el que se da respuesta a solicitud de acceso a la información acerca de la materia.

${ }^{69}$ Vid. dictámenes de la Contraloría General de la República, 04.12.2014, 094244N14; y 08.11.2017, $039401 \mathrm{~N} 17$.

${ }^{70}$ Véase artículo 71 inciso $6^{\circ}$ de la Ley 21.000, de 2017.

${ }^{71}$ Esto ha sido resuelto por la Corte Suprema al señalar que " $[\ldots .$.$] todos los actos administrativos -$ incluidos los sancionatorios, por cierto- producen sus efectos de manera inmediata, sus consecuencias jurídicas y materiales se radican en el patrimonio del administrado desde el momento mismo de su notificación, y, una vez notificado, la Administración puede exigir su cumplimiento, incluso antes de que la persona sancionada reclame de la legalidad del acto, salvo que la ley o el juez suspendan dicha exigibilidad -es decir, su eficacia, en términos de ejecutividad-, pero tal suspensión no dice relación con que los efectos del acto no se producen -esto es, no afecta su ejecutoriedad-, sino que, por el contrario, ellos se encuentran plenamente incorporados en el patrimonio del deudor desde su notificación y permanecen en tanto el juez que conozca de la reclamación no declare la ilegalidad del acto respectivo.", en Corte Suprema, 30.10.2014, rol No 1.079-2014, c. 11 .

${ }^{72}$ Respecto del tema, véase la sentencia de la Corte Suprema, 20.08.2014, rol No $11.317-2014$, c. $4^{\circ}$ de la sentencia de casación. 
No obstante, en otros supuestos normativos, la suspensión puede llegar a extinguir la sanción. Se trata de regulaciones legales específicas, cuyo objeto es paralizar el cumplimiento de la sanción impuesta, ello en atención a la concurrencia de las particularidades fácticas que han configurado el supuesto infraccional. Ahora bien, debido a sus singulares requisitos y efectos, requiere de una norma que expresamente la establezca.

Así, por ejemplo, el artículo 106 del Código Tributario señala que las sanciones pecuniarias "podrán” ser suspendidas, a juicio exclusivo del Director Regional, si el contribuyente probare que ha procedido con antecedentes que hagan excusable la acción u omisión en que hubiere incurrido o si el implicado se ha denunciado y confesado la infracción y sus circunstancias ${ }^{73}$. Si bien es una figura de carácter provisional y, por tanto, reversible, es posible que devenga en permanente si opera la prescripción de la acción ejecutiva de cobro, en caso de que la Administración decidiera posteriormente condonar la sanción o revocar el acto administrativo que la contiene.

\section{La sustitución de las medidas impuestas}

La sustitución es otro mecanismo susceptible de ser empleado en la etapa de ejecución de las sanciones administrativas. Para la doctrina comparada, la sustitución sería una especie de condonación consistente en la conmutación ${ }^{74}$ de la sanción por otra media de menor gravedad o incluso por medidas futuras que satisfagan los intereses públicos lesionados por la infracción, ya sea por razones de equidad o por la concurrencia de un interés general en el caso concreto ${ }^{75}$.

De la revisión de la legislación nacional se puede deprender que su objeto principal es reemplazar la sanción impuesta al particular por una medida diversa, generalmente programas de capacitación o de asistencia al cumplimiento de los deberes y obligaciones que establecen las leyes aplicables al sector.

El tal sentido, la normativa laboral contempla en el artículo 506 ter del Código del Trabajo la figura de la sustitución, la que opera tratándose de micro y pequeñas empresas, y en los casos en que el afectado no hubiere recurrido de conformidad a los artículos 503 y 511 de dicho Código, el inspector del trabajo respectivo autorizará, a solicitud del sancionado, y solo por una vez en el año respecto de la misma infracción, la sustitución de la multa impuesta por alguna de las modalidades allí indicadas, esto es, por la: 1) incorporación en un programa de asistencia al cumplimiento, en caso de infracciones a las normas de higiene y seguridad y 2) asistencia obligatoria a programas de capacitación dictados por la Dirección del Trabajo, en caso de infracciones diversas a las antes aludidas. Para el ejercicio de esta potestad, la Dirección del Trabajo emitió la Circular N $^{\circ}$ 58, de 2016, que modificó las instrucciones para la tramitación de las solicitudes de sustitución de multa por la incorporación de un programa de asistencia

73 Véase el inciso $1^{\circ}$ del artículo 106 del Código Tributario.

${ }^{74}$ En este sentido, por ejemplo, el artículo 20.3 de la LPSPV regula la posibilidad de conmutar la sanción impuesta por otra correspondiente a infracciones o categorías de infracciones de menor gravedad.

${ }^{75}$ CANO, 2018, p. 203. 
al cumplimiento y la puesta en marcha de un sistema de gestión de seguridad y salud en el trabajo y que dejó sin efecto la anterior circular pertinente a la materia ${ }^{76}$.

Asimismo, el $\mathrm{N}^{\circ} 3$ del artículo 165, del Código Tributario establece que si notificada la infracción o giro, según sea el caso, los contribuyentes acogidos al artículo 14 ter de la Ley sobre Impuesto a la Renta, podrán, por una única vez, solicitar la sustitución de la multa respectiva por la participación obligatoria del contribuyente o su representante a programas de capacitación en materias tributarias impartidos por el servicio de manera presencial o a distancia.

A nivel comparado, existen supuestos que se pueden vincular con esta medida, los que están conformados por aquellas disposiciones que prevén la reducción del importe de la multa impuesta en aquellos casos en los que el infractor responsable se adecue tardíamente a la normativa infringida. Con esta rebaja se busca incitar al cumplimiento de los deberes inicialmente desatendidos sin que la Administración se vea obligada a la ejecución de la medida ${ }^{77}$.

\section{CONCLusiones}

El principio de legalidad exige que toda sanción debe ser ejecutada en los términos previstos en el acto administrativo que la establece, sin embargo, nuestro ordenamiento jurídico ha previsto de distintos mecanismos que permiten a la autoridad administrativa revisar el acto administrativo sancionador sin llegar a ejecutar la sanción administrativa impuesta. En primer término, cuenta con los mecanismos generales de revisión, pudiendo invalidar aquellos actos sancionatorios contrarios a derecho; enseguida, puede disponer la revocación de la sanción, esto último, en la medida que en su ejercicio se adopten ciertas precauciones con el objeto de evitar incurrir en un supuesto de desviación de poder o en una infracción a la garantía constitucional de igualdad ante la ley. Junto con ello, la autoridad también puede declarar el decaimiento del acto sancionatorio.

Por su parte, a nivel sectorial, la ley ha dispuesto de mecanismos especiales para la revisión de las sanciones administrativas, lo que dependerá de las particulares circunstancias del sistema sancionador de que se trate y cuyo ejercicio estará supeditado a los particulares requisitos que la norma haya dispuesto. Ejemplo de ello lo son la condonación, la suspensión o sustitución de la sanción.

La aplicación de cualquiera de estos mecanismos debe ejercerse de manera razonable y debidamente motivada, de modo que su adopción responda: i) al principio de legalidad; ii) a la protección de un interés público, como sería evitar que la gravedad de la sanción impuesta ponga en peligro la continuidad de una empresa y con ello los puestos de trabajo de un número significativo de personas; iii) al principio de igualdad, por medio de una aplicación uniforme de estos mecanismos frente a situaciones

\footnotetext{
${ }^{76}$ Cuya legalidad había sido cuestionada por la Contraloría en su dictamen de 10.10.2014, 078775N14.

77 Rebollo Puig, 2010, p. 998.
} 
idénticas; iv) a una actuación lícita de la autoridad, ello en la medida que su ejercicio no contravenga el ordenamiento jurídico y, finalmente, v) a la necesidad de garantizar el respeto de los derechos o intereses legítimos, tanto del sujeto sancionado como de terceros (sujetos afectados por la ocurrencia de la infracción).

\section{BiBLIOGRAFÍA}

Bocanegra, Raúl, 1977: La revisión de oficio de los actos administrativos, Madrid: Instituto de Estudios de la Administración Local.

Bocksang Hola, Gabriel, 2011: "La dilación excesiva de los procedimientos administrativos sancionatorios: a horcajadas entre decaimiento y nulidad", en Sentencias Destacadas 2010 una mirada desde la perspectiva de las políticas públicas, Santiago, Libertad y Desarrollo, pp. 225-252.

Cano Campos, Tomás, 2018: Sanciones Administrativas, Madrid: Francis Lefebvre, 242 pp.

Cordero Quinzacara, Eduardo, 2014: Derecho Administrativo Sancionador. Bases y principios en el Derecho chileno, Santiago: Legal Publishing - Thomson Reuters - La Ley.

Cordero Vega, Luis, 2011: "El decaimiento del procedimiento administrativo sancionador: comentarios a las sentencias de la Corte Suprema del año 2010", en: Anuario de Derecho Público, Santiago: Universidad Diego Portales, pp. 243-255.

Cordero Vega, Luis, 2015: Lecciones de Derecho Administrativo, Santiago: Abeledo Perrot Thomson Reuters.

DANós OrdóñEz, Jorge, 2014: "La extinción de las infracciones y sanciones administrativas", en Danós Ordóñez, Jorge; Huapaya Tapia, Ramón; Rojas Montes, Verónica; Tirado Barrera, José Antonio y Vignolo Cueva, Orlando (Coordinadores), Derecho Administrativo: Innovación, cambio y eficacia, Lima: Thomson Reuters - La Ley pp. 14-37.

Evans Espiñeira, Eugenio y Poblete Ortúzar, Domingo, 2014: “¿Prescripción o decaimiento del procedimiento administrativo sancionador?; el caso de la industria eléctrica”, en Arancibia Mattar, Jaime y Alarcón Jaña, Pablo [Coord.]: Sanciones Administrativas, Santiago: Thomson Reuters - La Ley, pp. 217-237.

Flores Rivas, Juan Carlos, 2017: "La potestad revocatoria de los actos administrativos", en Revista de Derecho (Coquimbo), Año 24, No 1, pp. 191-222.

García de Enterría, Eduardo y Fernández, Tomás-Ramón, 2011: Curso de Derecho Administrativo, (15 $5^{\text {a }}$ edición), Tomo I, Madrid: Civitas - Thomson Reuters.

García-Trevijano Garnica, Ernesto, 1996: "Consideraciones sobre la revocación de actos administrativos no declarativos de derechos y de gravamen”, en Revista Española de Derecho Administrativo, $\mathrm{N}^{\circ}$ 91, pp. 415-436.

Gómez GonzÁlez, Rosa Fernanda, 2019: "El rol del denunciante en los procedimientos sancionatorios", en prensas.

GonZÁlez PÉrez, Jesús, 1972: “Dictamen sobre la extensión de los beneficios del Decreto de Indulto de 23 de septiembre de 1971 a las sanciones administrativas", en Revista de Derecho Urbanístico, $\mathrm{N}^{\circ} 26$.

GonzÁlez PÉREZ, Jesús, 1983: Comentarios al Reglamento de procedimiento económico-administrativo, Madrid: Civitas.

Huergo Lora, Alejandro, 2007: Las sanciones administrativas, Madrid: Iustel.

Lara Arroyo, José Luis y Guerrero Valle, Gonzalo, 2011: “Aspectos críticos de la invalidación administrativa en la Ley 19.880: análisis en la jurisprudencia de la Contraloría General de la República a 8 años de su vigencia”, en Revista de Derecho (Escuela de Postgrado), No 1, pp. 17-44. 
Lasagabaster Herrarte, Iñaki, 2010: "Causas de extinción de la responsabilidad”, en Lozano Cutanda, Blanca (dir.), Diccionario de sanciones administrativas, Madrid: Iustel, pp. 151-157. Lozano Cutanda, Blanca (dir.), 2010: Diccionario de sanciones administrativas, Madrid: Iustel.

Lozano CutANDA, Blanca, 1990: La extinción de las sanciones administrativas y tributarias, Madrid: Marcial Pons.

Morón Urbina, Juan Carlos, 2011: "La revocación de actos administrativos, interés público y seguridad jurídica”, en Revista Derecho (PUCP), No 67, pp. 419-455.

Muñoz Machado, Santiago (dir.), 2017: Diccionario Panhispánico del español jurídico, Volumen I, Madrid: Real Academia Española.

Nieto, Alejandro, 2012: Derecho Administrativo Sancionador, (5ª edición), Madrid: Tecnos.

Ortega SARCo, Eduardo, 2015: "La ausencia de una regulación general del indulto administrativo en el Ordenamiento Peruano", en Foro Jurídico, No 14, pp. 159-164.

Osorio, Cristóbal, 2016: Manual de Procedimiento Administrativo Sancionador, Santiago: Legal Publishing.

Parada Vásquez, José Ramón, 1989: Derecho Administrativo. Parte General, Tomo I, Madrid: Marcial Pons.

Parejo Alfonso, Luciano, 2013: Lecciones de Derecho Administrativo (6 ${ }^{a}$ edición), Valencia: Tirant lo Blanch.

Rebollo Puig, Manuel, 2010: "Sanciones pecuniarias", en Lozano Cutanda, Blanca (dir.), Diccionario de sanciones administrativas, Madrid: Iustel, pp. 985-1000.

SAnZ Rubiales, Íñigo, 1999: "Revocación de sanciones administrativas por motivos de oportunidad", en Revista de Administración Pública, No 148, pp. 359-385.

Sobrao Martínez, Francisco, 1978: "Las causas de extinción de la responsabilidad administrativa”, en Estudios de Derecho civil en honor al profesor Batlle Vázquez, Madrid: Revista de Derecho Privado.

Tola RúA, Miguel Ángel, 1999: "La consideración jurídica del denunciante en el procedimiento sancionador", en Actualidad administrativa, $\mathrm{N}^{\circ} 31$, pp. 839-858.

VALDivia, José Miguel y BlaKe, Tomás, 2015: "El decaimiento del procedimiento administrativo sancionatorio ante el Derecho administrativo", en: Estudios Públicos, No 138, pp. 93-135.

Villar Palasí, José Luis, 1955: "Poder de policía y precio justo. El problema de la tasa de mercado", en Revista de Administración Pública, Vol. 16, pp. 11-84.

Zanobini, Guido, 1958: Corso di didirtto amministrativo (8ª edición), Milan: Giuffrè. 
